\title{
Basic and Neutral Amino Acid Transport in Aspergillus nidulans
}

\author{
By M. PIOTROWSKA \\ Institute of Biochemistry and Biophysics, Polish Academy of Sciences, Warsaw \\ AND P. P. STEPIEŃ, E. BARTNIK AND E. ZAKRZEWSKA \\ Department of Genetics, Warsaw University, Warsaw, Poland
}

(Received 5 May 1975; revised 7 July 1975)

SUMMARY

\begin{abstract}
Arginine and methionine transport by Aspergillus nidulans mycelium was invest1gated.

A single uptake system is responsible for the transport of arginine, lysine and ornithine. Transport is energy-dependent and specific for these basic amino acids. The $K_{m}$ value for arginine is $\mathrm{I} \times 10^{-5} \mathrm{M}$, and $V_{\max }$ is $2.8 \mathrm{nmol} / \mathrm{mg}$ dry wt $/ \mathrm{min} ; K_{m}$ for lysine is $8 \times 10^{-6} \mathrm{M} ; K_{i}$ for lysine as inhibitor of arginine uptake is $12 \mu \mathrm{M}$, and $K_{i}$ for ornithine is $3 \mathrm{mM}$.

On minimal medium, methionine is transported with a $K_{m}$ of $0.1 \mathrm{mM}$ and $V_{\max }$ about I $\mathrm{nmol} / \mathrm{mg}$ dry $\mathrm{wt} / \mathrm{min}$; transport is inhibited by azide. Neutral amino acids such as serine, phenylalanine and leucine are probably transported by the same system, as indicated by their inhibition of methionine uptake and the existence of a mutant specifically impaired in their transport.

The recessive mutant nap3, unable to transport neutral amino acids, was isolated as resistant to selenomethionine and $p$-fluorophenylanine. This mutant has unchanged transport of methionine by general and specific sulphur-regulated permeases.
\end{abstract}

\section{INTRODUCTION}

Several amino acid permeases have been described and characterized in the filamentous fungi Neurospora crassa and Penicillium chrysogenum. Results concerning amino acid uptake in Aspergillus nidulans are less complete. Robinson, Anthony \& Drabble (1973a) and Pateman, Kinghorn \& Dunn (1974) characterized an acidic amino acid permease. Sinha (1969) described a transport system for phenylalanine. Cybis \& Weglenski (I969) demonstrated that lysine and arginine compete for entry into the $A$. nidulans mycelium, and suggested a single permease for transport of these two amino acids. Hackette et al. (1970) and Benko, Wood \& Segel (1967) showed the development of a methionine transporting system during sulphur starvation and the derepression of uptake systems for amino acids resulting from nitrogen and carbon deficiency.

Contrary to the situation in Neurospora where mutants have been isolated for most of the transporting systems, no permease mutation is known for Penicillium and few for Aspergillus. In $A$. nidulans, Sinha (1969) described a dominant mutation which was impaired in the transport of phenylalanine and to some degree in the transport of most of the amino acids. Kinghorn \& Pateman (1975) isolated recessive mutants blocked in the transport of acidic amino acids and dominant and recessive mutants impaired simultaneously in acidic and neutral amino acid uptake.

This paper characterizes the transport of arginine, lysine and ornithine by the basic amino acid permease of $A$. nidulans. 
Data concerning the transport of methionine under different growth conditions are presented and discussed, and methionine transport by a neutral amino acid permease distinct from the sulphur- and nitrogen-regulated permeases is suggested. A recessive mutation specifically impaired in this system is described.

\section{METHODS}

Strains. All experiments were carried out with the same strain of $A$. nidulans pabaAr, biAI (auxotrophic for vitamins p-aminobenzoic acid and biotin). The same strain was used for mutagenesis.

Genetic methods and media were standard ones used for $A$. nidulans (Pontecorvo et al. I953; Cove, 1966). Liquid media containing no nitrogen source ( $-\mathrm{N}$ medium), no carbon source ( $-\mathrm{G}$ medium) and no sulphur ( $-\mathrm{S}$ medium) were also used.

Transport assay. In a typical experiment the standard minimal, medium (MM) was inoculated with a heavy conidial suspension of about $10^{7}$ conidia/ml and grown in an orbital shaker at $32{ }^{\circ} \mathrm{C}$. Young mycelium ( 14 to $\mathrm{I} 6 \mathrm{~h}$ old) was used, usually at about $\mathrm{I} . \mathrm{mg}$ dry $\mathrm{wt} / \mathrm{ml}$. Without changing the medium, $25 \mathrm{ml}$ portions of cultures were transferred by pipette to an Erlenmeyer flask in a water bath; the flask already contained the radioactive substrate $(0.2 \mathrm{mM}, 0.1$ to $0.2 \mathrm{mCi} /$ assay). Samples ( 3 to $5 \mathrm{ml}$ ) were withdrawn with a pipette every $30 \mathrm{~s}$ during a $2 \mathrm{~min}$ period from shaken cultures, filtered under suction through preweighed Whatman GF 85 filters and washed immediately with $20 \mathrm{ml}$ of ice-cold water. Filters with mycelium were dried for $24 \mathrm{~h}$ at $90^{\circ} \mathrm{C}$, weighed to calculate the dry weight of each mycelial sample, placed in vials with $5 \mathrm{ml}$ of Packard Permablend III scintillation mixture, and the radioactivity was measured in a Beckman LS I50 scintillation counter. The quenching of the radioactivity was calculated for the conditions used and found to be $50 \%$. All results were corrected to absolute d.p.m. values.

Transport rates are expressed as nmol substrate/mg dry $\mathrm{wt} / \mathrm{min}$.

Protein incorporation. Two duplicate samples were taken every $30 \mathrm{~s}$ during a $3 \mathrm{~min}$ period, as for the transport assay. Samples were extracted immediately with $5 \%(\mathrm{w} / \mathrm{v})$ cold trichloroacetic acid (TCA), filtered, and radioactivity was measured in both filtrate and precipitate. Parallel untreated samples were counted for the total radioactivity accumulated.

Chromatography of extracts. After 2 to $3 \mathrm{~min}$ incubation with radioactive substrates $(0.2 \mathrm{mM}, 0.2 \mathrm{mCi})$ the mycelium was harvested, washed with ice-cold water and extracted immediately with $5 \%$ TCA. After centrifugation, the radioactivities of a portion of the supernatant and of the pellet were assayed. The supernatant was applied to a Dowex $50 \mathrm{H}^{+}$ column and elution was carried out with $2 \mathrm{M}-\mathrm{NH}_{4} \mathrm{OH}$. The amino acid fraction eluted was evaporated to dryness and resuspended in $1 / 10$ vol. of distilled water. All radioactivity applied was recovered from the columns in this procedure. Samples $(5 \mathrm{ml})$ were then submitted to thin-layer chromatography on plates of MN 300 cellulose and developed with propanol-85\% formic acid-water (40:2:I, by vol.). Chromatograms were stained with ninhydrin and the positions of amino acids were identified using external and internal standards. Chromatograms were then scanned for radioactivity with a Berthold automatic thin-layer scanner.

Chemicals. $\mathrm{L}-\left[\mathrm{U}-{ }^{14} \mathrm{C}\right]$ arginine- $\mathrm{HCl}$, specific activity $336 \mathrm{mCi} / \mathrm{mmole}$, and L-methyl-[ $\left[{ }^{14} \mathrm{C}\right]-$ methionine, $60 \mathrm{mCi} / \mathrm{mmole}$, were obtained from the Radiochemical Centre, Amersham, Buckinghamshire. All other L-[U-14 C]amino acids were from UVVVR, Czechoslovakia. The remaining chemicals were of commercial grade. 


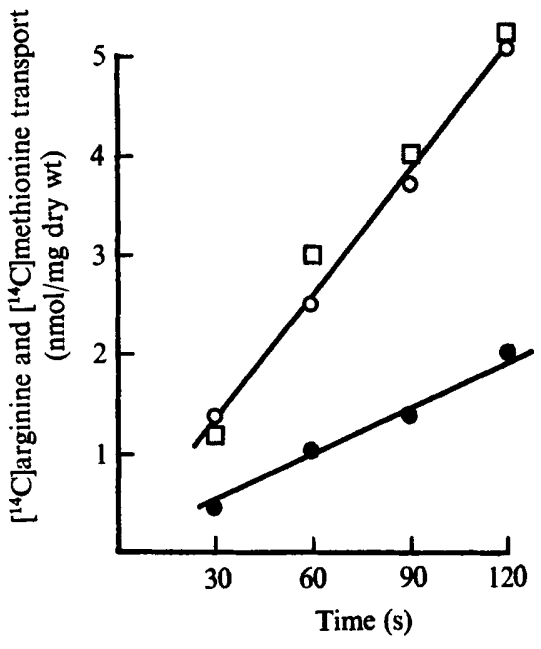

Fig. I

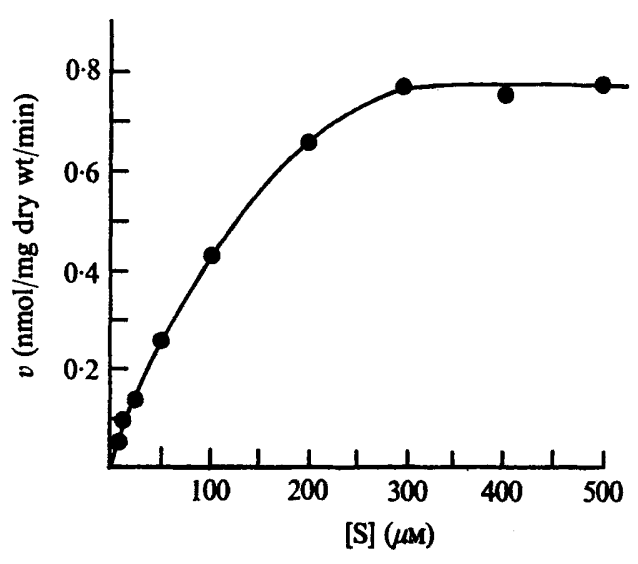

Fig. 2

Fig. I. Time-dependence of $\left[{ }^{14} \mathrm{C}\right]$ arginine and $\left[{ }^{14} \mathrm{C}\right]$ methionine transport by mycelia of the wild type and of mutant aga65, which lacks arginase. $O,\left[{ }^{14} \mathrm{C}\right]$ arginine, wild type; $\square,\left[{ }^{14} \mathrm{C}\right]$ arginine, mutant aga65; 0, [19 $\mathrm{C}]$ methionine, wild type.

Fig. 2. Kinetics of [ $\left.{ }^{14} \mathrm{C}\right]$ methionine transport by mycelium. Direct plot of the initial velocity of transport as the function of varying concentrations of amino acid.

\section{RESULTS}

\section{Transport of basic amino acids}

Linearity of the assay and pH optimum. Figure I shows the linear time-dependence of $\left[{ }^{14} \mathrm{C}\right]$ arginine transport under standard conditions during the 2 min assay period. Transport of the amino acid was inhibited more than $90 \%$ in the presence of $\mathrm{I}$ mM-sodium azide added $2 \mathrm{~min}$ before the substrate, indicating that transport is energy-dependent.

The optimal $\mathrm{pH}$ was about 5.0 to 5.5 (Fig. 3); the $\mathrm{pH}$ of the medium in standard experiments is about $6 \cdot 5$ to $7 \cdot 0$.

Metabolism of arginine during the transport assay period and incorporation into protein. About $95 \%$ of the total transported radioactivity was found to be extractable into cold TCA, while about $5 \%$ was found in the TCA precipitates during the $3 \mathrm{~min}$ following the addition of radioactive substrate.

Cycloheximide (10 $\mu \mathrm{g} / \mathrm{ml}$ ) inhibits protein synthesis in $A$. nidulans (Robinson, Anthony \& Drabble, $1973 b$ ). No difference in velocity of transport was found in the presence and absence of the antibiotic (10 $\mu \mathrm{g} / \mathrm{ml}$ ) during the first $3 \mathrm{~min}$ following addition of $\left[{ }^{14} \mathrm{C}\right]-$ arginine. TCA extracts were prepared after $3 \mathrm{~min}$ incubation of mycelium with $\left[{ }^{14} \mathrm{C}\right]-$ arginine and desalted on a Dowex $50 \mathrm{H}^{+}$column. All radioactivity (within a $5 \%$ range of error) was recovered from the column into the eluate. Only one peak of radioactivity was found on the chromatogram, identified as arginine. Thus, more than $90 \%$ of the radioactivity in the extractable pool was still in the form of free, unmetabolized arginine.

The rate of arginine transport was unchanged (Fig. I) in mutant aga65, which lacks arginase, the first enzyme of arginine catabolism (unpublished).

These results indicate that the initial velocity of transport measured is not dependent on arginine being catabolized and/or incorporated into protein.

Kinetics of $\left[{ }^{14} \mathrm{C}\right]$ arginine transport. The dependence of initial velocity of transport on 


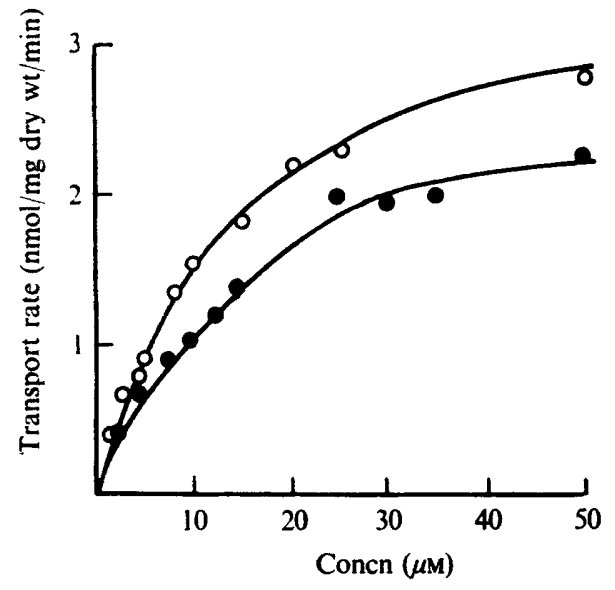

Fig. 3

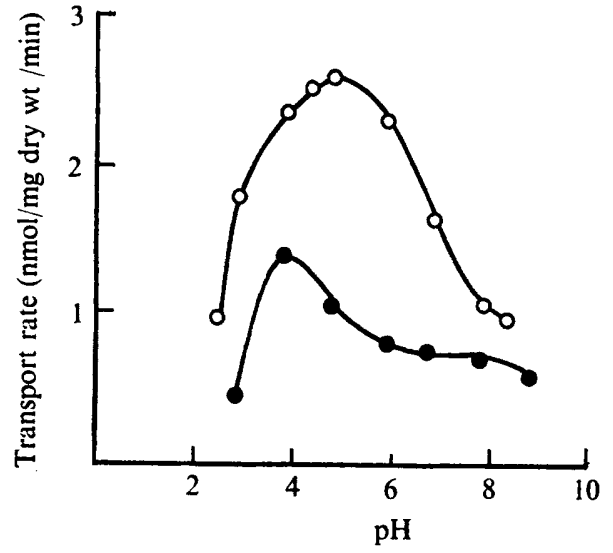

Fig. 4

Fig. 3. $\left[{ }^{14} \mathrm{C}\right]$ arginine and $\left[{ }^{14} \mathrm{C}\right]$ methionine transport as a function of $\mathrm{pH}$ value. Citrate-phosphate, potassium phosphate and tris- $\mathbf{H C l}$ buffers were added to the medium at a final concentration of $0 . \mathrm{I} \mathrm{M}$, to obtain the indicated $\mathrm{pH}$. $\mathrm{O}$, Initial rate of $\left[{ }^{14} \mathrm{C}\right]$ arginine transport; $O$, initial rate of $\left[{ }^{14} \mathrm{C}\right]$ methionine transport.

Fig. 4. Kinetics of $(O)\left[{ }^{14} \mathrm{C}\right]$ arginine and $(O)\left[{ }^{14} \mathrm{C}\right]$ lysine transport by mycelium. Direct plot of the initial velocity of transport as the function of varying amino acid concentrations.

\section{Table I. Effect of unlabelled amino acids on $\left[{ }^{14} \mathrm{C}\right]$ arginine and $\left[{ }^{14} \mathrm{C}\right]$ methionine uptake}

The [ ${ }^{14} \mathrm{C}$ ]arginine concentration was $25 \mu \mathrm{M}$, and the $\left[{ }^{14} \mathrm{C}\right.$ ]methionine concentration was 25 or $200 \mu \mathrm{M}$. Unlabelled amino acids, together with either arginine or methionine, were added at the same time as the labelled substrate.

\begin{tabular}{|c|c|c|c|}
\hline \multicolumn{4}{|c|}{ Arginine } \\
\hline & \multicolumn{3}{|c|}{ Percentage inhibition ${ }^{*}$} \\
\hline Inhibitor & 10 & 100 & 1000 \\
\hline Lysine & 90 & & \\
\hline Ornithine & 0 & IO & 65 \\
\hline Histidine & 0 & 13 & 20 \\
\hline Methionine & I I & 10 & \\
\hline Leucine & 3 & I 2 & \\
\hline Phenylalanine & 15 & 25 & \\
\hline Alanine & 0 & 0 & \\
\hline Glutamate & 0 & 0 & \\
\hline Proline & 0 & 0 & \\
\hline
\end{tabular}

\begin{tabular}{lcc}
\multicolumn{3}{c}{ Methionine } \\
Inhibitor & $\overbrace{10}^{\text {Percentage inhibition* }}$ & 100 \\
Leucine & 40 & 60 \\
Alanine & 65 & 75 \\
Serine & 62 & 85 \\
O-acetylserine & 85 & \\
Phenylalanine & 63 & \\
Glutamine & 60 & \\
Arginine & 10 & \\
Glutamate & 0 & \\
Proline & 0
\end{tabular}

* Percentage inhibition at inhibitor: substrate ratios of 10, 100 or 1000.

substrate concentration is shown in Fig. 4. The system was saturable and only one system seemed to be involved for the concentrations tested. The $K_{m}$, calculated from the reciprocal Lineweaver-Burke plot, was about Io $\mu \mathrm{M}$ and $V_{\max }$ was about $2.8 \mathrm{nmol} / \mathrm{mg}$ dry wt $/ \mathrm{min}$.

Kinetics of $\left[{ }^{14} \mathrm{C}\right]$ lysine transport. Figure 4 shows the direct plot of velocity-concentration dependence for transport of $\left[{ }^{14} \mathrm{C}\right] l y s i n e$. The $K_{m}$ calculated from this was about $8 \mu \mathrm{M}$, and $V_{\max }$ was about $2 \mathrm{nmol} / \mathrm{mg}$ dry $\mathrm{wt} / \mathrm{min}$.

Specificity of the arginine transport system. The effect of several unlabelled L-amino acids on the uptake of $\left[{ }^{4} \mathrm{C}\right]$ arginine is shown in Table $\mathrm{I}$. Only lysine was a good inhibitor. The 


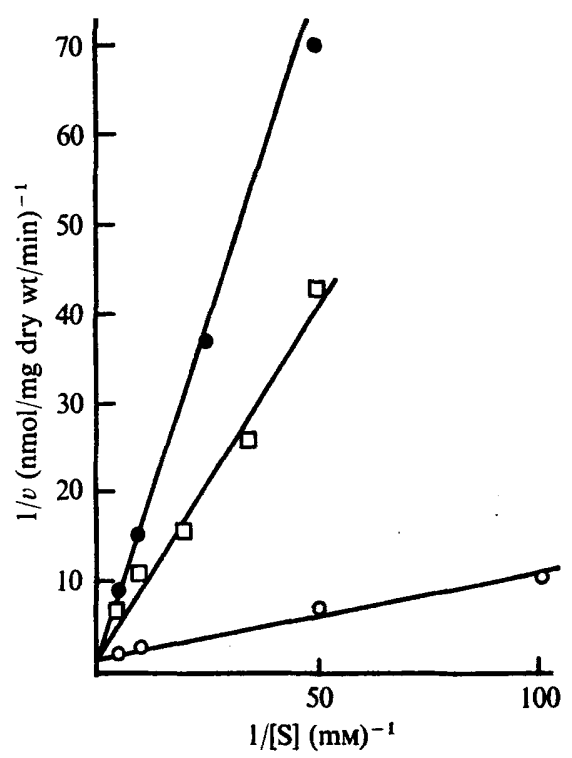

Fig. 5

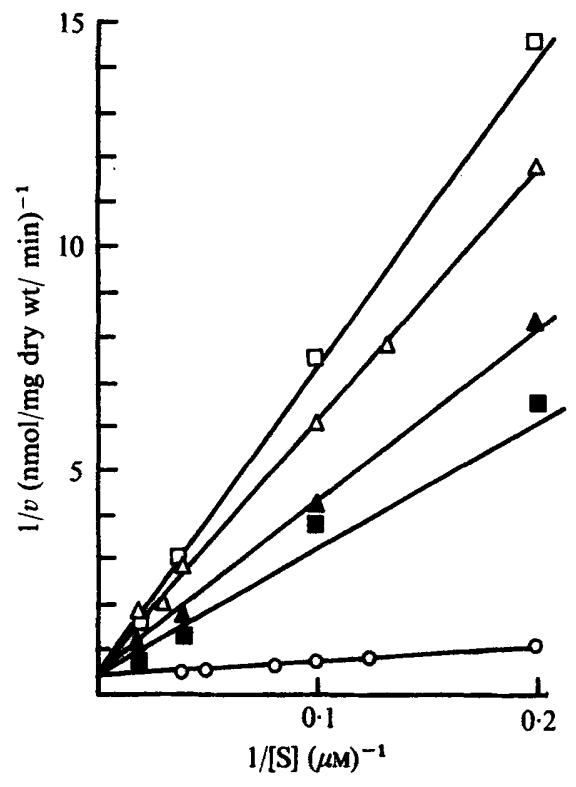

Fig. 6

Fig. 5. Competitive inhibition of $\left[{ }^{14} \mathrm{C}\right]$ arginine transport by unlabelled L-lysine and L-ornithine. $O$, No inhibitor; $\square, 0.1$ mM-lysine present; $\square, 0.2$ mM-lysine present; $\Delta, 4 \mathrm{~mm}$ L-ornithine present; $\triangle, 12 \mathrm{mM}$ L-ornithine present.

Fig. 6. Competitive inhibition of [ $\left.{ }^{14} \mathrm{C}\right]$ methionine transport by unlabelled L-serine and $O$-acetyl-Lserine. $O$, No inhibitor; $\square, 2 \mathrm{mM}$ L-serine present; $O$, $10 \mathrm{mM} O$-acetyl-L-serine present.

basic amino acids ornithine and histidine did not inhibit transport at Ioo-fold excess (i.e. at 100 times the substrate concentration), though inhibition by ornithine was observed at 1000-fold excess. The results of competition studies (Fig. 5) show that inhibition by the basic amino acids ornithine and lysine is of the competitive type. Dixon plots of inhibition data gave a $K_{i}$ value for lysine as inhibitor of arginine uptake of $12 \mu \mathrm{M}$, and a $K_{i}$ value for ornithine as an inhibitor of arginine transport of about $3 \mathrm{mM}$. The $K_{m}$ values for arginine and lysine and the $K_{i}$ of lysine as the inhibitor of arginine were roughly equal, which suggests competition for the same site of permease, which had equal affinity for these amino acids. Given the competitive nature of inhibition of arginine transport, it may be assumed that the same basic amino acid permease is responsible for transporting ornithine but probably with a distinctly lower activity.

\section{Transport of methionine}

Linearity of the assay and pH optimum. Figure I shows the linear time-dependence of $\left[{ }^{14} \mathrm{C}\right]$ methionine transport. The transport rate was linear during the $2 \mathrm{~min}$ assay period. Sodium azide (I $\mathrm{mM}$ ) added $2 \mathrm{~min}$ before the labelled substrate inhibited transport more than $90 \%$, indicating that transport is energy-dependent.

The $\mathrm{pH}$ optimum was about 4.0 to 4.5 (Fig. 3 ).

Metabolism of methionine during the assay period. Incorporation of radioactivity into the protein was assayed as described in Methods. Within the first 3 min following the addition of $\left[{ }^{14} \mathrm{C}\right]$ methionine the total amount of radioactivity in the TCA precipitates did not exceed I to $2 \%$ of the total radioactivity accumulated in the mycelium. TCA extracts prepared after $3 \mathrm{~min}$ incubation of mycelium with $\left[{ }^{14} \mathrm{C}\right]$ methionine were applied to thin-layer 
chromatography plates. On the chromatogram about $60 \%$ of the radioactivity applied was found in the peak corresponding to free methionine, and the rest was in other unidentified compounds. Thus, during the $2 \mathrm{~min}$ assay about $60 \%$ or more of transported methionine still remained in the unmetabolized form.

Kinetics of methionine transport. Figure 2 shows the direct plot of velocity-concentration dependence of methionine transport. For the range of concentration used only one system seems to be involved. From Fig. 2, the $K_{m}$ was calculated to be about $10 \mathrm{mM}$ and $V_{\max }$ to be 0.8 to $\mathrm{I} \cdot 0 \mathrm{nmol} / \mathrm{mg}$ dry $\mathrm{wt} / \mathrm{min}$.

Specificity of the transporting system. Table I shows the results of inhibition tests performed with several unlabelled L-amino acids added simultaneously with $\left[{ }^{14} \mathrm{C}\right]$ methionine at 10 and 100 times the concentration of the substrate. There was no more than $10 \%$ inhibition by basic and acidic amino acids, and by proline. Robinson et al. (1973a) demonstrated that there is a highly specific permease for acidic amino acids in Aspergillus. Proline does not inhibit neutral, basic or acidic amino acid transport and is probably transported by its own specific system (unpublished). The lack of inhibition by arginine is in agreement with results presented in this paper on transport of basic amino acids. Neutral amino acids tested inhibited methionine transport by at least $40 \%$ at Io-fold excess, suggesting their transport by a common system. The character of inhibition of methionine transport was tested further for serine and $O$-acetylserine (Fig. 6), and was of the competitive type.

\section{Neutral amino acid transport by a mutant}

Selection and characterization of the mutant. Aspergillus nidulans is highly resistant to most of the amino acid analogues used for the selection of permease mutations (e.g. canavanine or ethionine). We found that selenomethionine (S-Meth), a methionine analogue, slows the growth of $A$. nidulans at a concentration of $0.2 \mu \mathrm{M}$ and at $100 \mu \mathrm{M}$ stops the growth completely. The effect is specific, as indicated by reversion of toxicity by equimolar methionine. $p$-Fluorophenylalanine (PFA) is a toxic analogue of phenylalanine, widely used in studying the genetics of $A$. nidulans. Mutants resistant simultaneously to $0 \cdot 1 \mathrm{mM}-\mathrm{S}$-Meth and I mM-PFA were selected after u.v. mutagenesis and one of them (nap3) was studied further.

Mutant nap 3 was tested in heterokaryons and diploids against the wild type and was found to be totally recessive. The strain bearing the nap 3 mutation was crossed with the wild type and the mutation was found to be monogenic.

Transport of amino acids by the nap 3 mutant. Transport rates of various amino acids under different growth conditions were studied. $\left[{ }^{14} \mathrm{C}\right]$ methionine, $\left[{ }^{14} \mathrm{C}\right]$ phenylalanine and $\left[{ }^{14} \mathrm{C}\right]-$ leucine were not transported by mycelium of nap 3 growing on the standard minimal medium, whereas $\left[{ }^{14} \mathrm{C}\right]$ arginine and $\left[{ }^{14} \mathrm{C}\right]$ proline were.

Under nitrogen starvation, mutant nap 3 became capable of normal transport of $\left[{ }^{14} \mathrm{C}\right]-$ methionine and $\left[{ }^{14} \mathrm{C}\right]$ phenylalanine, and transport of these amino acids was inhibited $90 \%$ by a ro-fold excess of unlabelled arginine. In the wild type and mutant nap 3 after $9 \mathrm{~h}$ of nitrogen starvation, the transport rate of arginine increased and it became sensitive to inhibition by methionine.

When the nap 3 strain was starved on $-G$ medium it became capable of $\left[{ }^{14} \mathrm{C}\right]$ methionine and $\left[{ }^{14} \mathrm{C}\right]$ phenylalanine transport. Transport on both $-\mathrm{N}$ and $-\mathrm{G}$ media was inhibited by I mM-azide. The general, non-specific system(s) of amino acid transport remained unchanged in the mutant.

When nap 3 was subjected to sulphur starvation it developed the capability to transport methionine, as in the wild type, but not phenylalanine. This last result enabled us to distinguish between the specific permease regulated by sulphur level in the medium, and the 
system of transport of neutral amino acids by which methionine, leucine and phenylalanine enter during growth on minimal medium. The results indicate that, on minimal medium, the sulphur-regulated permease is not present.

\section{DISCUSSION}

The results indicate that on minimal medium the same permease is responsible for the active transport of arginine, lysine and ornithine; arginine and lysine compete with equal affinity for the same site. Such a system seems to be similar to the basic amino acid permeases of other filamentous fungi such as Penicillium (Hunter \& Segel, 197I) and Neurospora (Pall, 1970); $K_{m}$ values found for arginine and lysine are of same order as those of Penicillium. This demonstration of a single permease for arginine, lysine and ornithine in $A$. nidulans is in agreement with the results of the growth studies of Cybis \& Weglenski (I969).

At neutral $\mathrm{pH}$ and under the standard conditions of growth used in our experiments, histidine did not significantly inhibit uptake of arginine even at 1000-fold excess. Basic permeases of both Penicillium and Neurospora have a very low affinity for histidine and this amino acid is probably mainly transported by a general system (Pall, 1970; Hunter \& Segel, 1971).

Derepression of methionine transport during sulphur, nitrogen or carbon starvation, and a highly specific methionine permease operating in sulphur-starved mycelium have been described for both Penicillium and Aspergillus by Benko et al. (1967). In Neurospora, on minimal medium, a single permease is mainly responsible for the transport of methionine and all neutral amino acids. In Penicillium, Benko et al. (1967) showed the lack of such a neutral amino acid permease and suggested that the highly specific methionine permease, derepressing upon sulphur starvation, is probably also responsible for methionine entry during the growth on minimal medium. However, Hunter \& Segel (1973) suggested that, on minimal medium, neutral amino acid uptake may be due to free diffusion through the lipophilic membrane.

The results on the specificity of permeases developing in wild type and mutant nap 3 in different growth conditions suggest that methionine is transported by a neutral amino acid permease during growth in nutrient-sufficient medium. This permease is absent from mutant nap 3 and is different from the general permease derepressed during nitrogen or carbon starvation and also different from the system for methionine transport which is derepressed during sulphur starvation.

This work was supported by the Polish Academy of Sciences within project 09.3.I.

\section{REFERENCES}

Benko, P. V., Wood, T. C. \& Segri, J. H. (1967). Specificity and regulation of methionine transport in filamentous fungi. Archives of Biochemistry and Biophysics 122, 783-804.

COVE, D. J. (1966). The induction and repression of nitrate reductase in Aspergillus nidulans. Biochimica et biophysica acta $113,51-56$.

CYBIS, J. \& WEGLENSKI, P. (1969). Effects of lysine on arginine uptake and metabolism in Aspergillus nidulans. Molecular and General Genetics ro4, 282-287.

Hackette, S. L., Skye, G. E., Burton, C. \& Segel, J. H. (1970). Characterization of an ammonium transport system in filamentous fungi with methylammonium $-{ }^{14} \mathrm{C}$ as the substrate. Journal of Biological Chemistry 245, 4241-4250.

Hunter, D. R. \& SegeL, J. H. (1971). Acidic and basic amino acid transport systems of Penicillium chrysogenum. Archives of Biochemistry and Biophysics 144, 168-183.

Hunter, D. R. \& SEGEL, J. H. (1973). Control of the general amino acid permease of Penicillium chrysogenum by transinhibition and turnover. Archives of Biochemistry and Biophysics 154, 387-399. 
Kinghorn, J. R. \& Pateman, J. A. (1975). Mutations which affect amino acid transport in Aspergillus nidulans. Journal of General Microbiology 86, $174-184$.

Pall, M. L. (1970). Amino acid transport in Neurospora crassa. II. Properties of a basic amino acid transport system. Biochimica et biophysica acta 203, 139-149.

Pateman, J. A., KInghorn, J. R. \& DUNN, E. (1974). Regulatory aspects of L-glutamate transport in Aspergillus nidulans. Journal of Bacteriology 129, 534-542.

Pontecorvo, C., Roper, J. A., Hemmons, L. M., MacDonald, K. D. \& Bufton, A. W. J. (1953). The genetics of Aspergillus nidulans. Advances in Genetics 5, 14I-238.

Robinson, J. H., Anthony, C. \& Drabble, W. T. (1973a). The acidic amino acid permease of Aspergillus nidulans. Journal of General Microbiology 79, 53-63.

Robinson, J. H., ANTHONY, C. \& Drabble, W. T. (1973 b). Regulation of the acidic amino acid permease of Aspergillus nidulans. Journal of General Microbiology 79, 65-80.

SinHA, W. (1969). Genetic control of the uptake of amino acids in Aspergillus nidulans. Genetics 62, 495-505. 